Revista Voluntas: estudos sobre Schopenhauer - $1^{\mathrm{o}}$ semestre 2011 - Vol. 2 - No 1 - ISSN: 2179-3786 - pp. 22-31

\title{
Sobre a atribuição de valor moral em Schopenhauer
}

\author{
Marcello G. Cavasin \\ Graduado em Filosofia pela UNICAMP
}

RESUMO: Em "Sobre o fundamento da moral", Schopenhauer admite como critério para que uma ação seja dotada de valor moral "a ausência de toda a motivação egoísta" ${ }^{1}$ Essa assertiva é, propriamente dizendo, o critério seguro para a atribuição ou não de valor moral às ações. Assim, ela mostra que à base de toda ação moral está a motivação não egoísta. Dessa maneira, a asserção "a ausência de toda motivação egoísta é, portanto, o critério de uma ação dotada de valor moral" 2 é, a bem dizer, uma forma resumida da resposta à questão posta a prêmio pela Real Sociedade Dinamarquesa, à qual "Sobre o fundamento da moral" é escrito concorrente. Começamos, assim, pela resposta, pelo critério que permite atribuir ou não valor moral. Admitindo o critério, nossa linha argumentativa perpassará os argumentos schopenhauerianos, iniciando com a valoração moral, depois, pela possibilidade de existência de ações morais e concluindo com o fundamento metafísico da moral, de modo que, ao propor questões sobre os argumentos do filósofo, sejamos por elas guiados.

PALAVRAS CHAVE: Schopenhauer; Moral; Metafísica.

ABSTRACT: In "On the basis of morality", Schopenhauer admits as a criterion for an action to be endowed with moral value the absence of any selfish motivation. This assumption is the reliable criterion for assigning moral values to the actions, and it shows that the basis of all moral action is not selfish motivation. Thus, the assertion "the absence of any selfish motivation is therefore the criterion for an action to be endowed with moral value" is, indeed, a concise response to the question posed to the prize by the Royal Danish Society, and the "On the basis of morality" is written competitor. So, we begin with the response, with the criterion for assigning moral value or not. Assuming the criterion, we will pervade schopenhauerian argument starting with the moral valuation, then by the possibility of moral action and, concluding, with the metaphysical foundation of morality. So that, the questions that we propose about the philosopher's arguments should guide us.

KEYWORDS: Schopenhauer; Moral; Metaphysics.

\section{Sobre o valor moral}

Para dar início à nossa análise, enunciamos a seguinte questão: qual ação, ou, a que tipo de ação se atribui valor moral? A resposta já nos está dada: o valor moral se atribui às ações não motivadas egoisticamente, quer dizer, em vista do interesse próprio do sujeito que age, em vista de seu bem-estar. Na sequência argumentativa, o próprio Schopenhauer acrescenta - prevendo as possíveis contra-argumentações - "pode-se objetar decerto que

\footnotetext{
${ }^{1}$ SCHOPENHAUER, A.. Sobre o fundamento da moral. $\$ 15$ p.131. Doravante "Sobre o fundamento da moral" (Über die Grundlage der Moral ) será abreviado como "M".

${ }^{2}$ SCHOPENHAUER, A. M, § 15, p.131.
} 
também as ações por pura maldade e crueldade não são interessadas”3, pois, de acordo com o próprio critério definido pelo filósofo, tais ações também possuiriam valor moral, isso porque não visam ao interesse próprio, mas sim ao sofrimento alheio, quer dizer, são ações que têm por escopo o mal-estar do outro - indiferentemente se isso causará prazer ou sofrimento ao sujeito da ação - pois, o "em vista de" da ação, a finalidade, não é, no caso de uma ação puramente má ou cruel, o interesse próprio, mas o sofrimento alheio. Ora, como tipo de ação desinteressada, a maldade e a crueldade devem, também, receber valoração moral. Mas esse não é o caso. Schopenhauer completa: “acrescenta-se, como uma característica bem íntima e não tão evidente das ações dotadas de valor moral, o fato de que elas deixam ficar um certo contentamento com nós mesmos que é chamado de aplauso da consciência. Do mesmo modo, as ações de injustiça e desamor que lhe são contrárias, mormente as de maldade e crueldade, experimentam uma auto apreciação

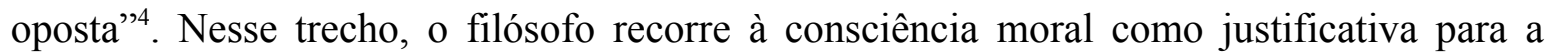
exclusão das ações maldosas e cruéis da valoração moral. Nossa primeira questão é a seguinte: se nosso juízo moral se funda na motivação egoísta ou não da ação, como a consciência moral pode atribuir ou não valor moral a algo para fora do critério previamente estabelecido? E mais, se é, a consciência moral - por meio do sentimento de contentamento, o "aplauso da consciência" -, capaz de determinar o valor moral das ações, qual é, então, o fundamento deste sentimento moral, quer dizer, o que está na base da consciência moral?

\section{Sobre a existência das ações morais}

Adotemos, pois, o critério dado ao nosso juízo para a atribuição de valor moral às ações, qual seja, a ausência de motivação egoísta; e, adotemos também, a regulação da consciência moral, e privemos de valor moral as ações de pura maldade e crueldade, que são as que têm o mal-estar alheio como último fim. Determinemos, agora de maneira positiva, que possuem valor moral apenas as ações de pura justiça espontânea e caridade desinteressada. Esse tipo de ação existe de fato? Não seria toda generosidade, toda justiça, toda caridade, toda honestidade, apenas convencionais e, portanto, egoístas?

\footnotetext{
${ }^{3}$ SCHOPENHAUER, A. M, $\S 15$, p. 131 .

${ }^{4}$ SCHOPENHAUER, A. M, § 15, p.131.
} 
Schopenhauer concebe o egoísmo como potência de tal forma arrebatadora que o define como "a motivação principal e fundamental" 5 tanto no animal quanto no homem. Assim o egoísmo ocorre quando a vontade busca a própria satisfação. Mas, o que é mais natural à vontade do que ser o ímpeto à sua própria satisfação? Tendo isso em vista, há, ainda, possibilidade de se agir moralmente? Não seriam toda justiça e caridade apenas ações egoístas mascaradas, isto é, ações que aparentemente visam ao bem alheio, mas que se fundam, sobretudo, no interesse e bem-estar do próprio sujeito da ação?

A isto Schopenhauer responde:

Quanto à maioria das ações justas, isto é realmente verdadeiro e certo (...). Que também seja verdadeiro quanto à parte considerável das ações caritativas, não resta dúvida, pois elas muitas vezes provêm da ostentação e muitas vezes da crença numa retribuição futura elevada ao quadrado e mesmo ao cubo, deixando ainda de lado outros motivos egoístas. Mas também é certo que há ações feitas por caridade desinteressada e por justiça espontânea. Referindo-me apenas à experiência e não aos fatos de consciência, são provas dessas últimas ações os casos isolados mais indubitáveis em que, não havendo nem o perigo da perseguição legal nem também da descoberta e de qualquer suspeita, foi, não obstante, dado pelo pobre ao rico o que lhe pertencia ${ }^{6}$.

Foquemos nossa atenção no período "referindo-me apenas à experiência e não aos fatos de consciência". Nele, Schopenhauer indica que a certeza da existência das ações caritativas não são "fatos de consciência", ou seja, não se trata de conhecimento imediato, mas apenas um dado da experiência, portanto, conhecimento empírico. No entanto, a experiência externa da ação não dá a conhecer a intenção íntima da vontade do indivíduo; outras palavras, a via empírica não expressa - de maneira imediata - o que motivou o agente da ação. Como, então, é possível deduzir dessa via empírica a certeza indubitável da ocorrência de ações morais? A que a ciência moral pode recorrer para garantir que existem de fato ações morais? Segundo Schopenhauer, no tomo I, livro I de O Mundo Como Vontade e Como Representação, referindo-se ao método científico:

\footnotetext{
${ }^{5}$ SCHOPENHAUER, A. M, § 14, p.120.

${ }^{6}$ SCHOPENHAUER, A. M, § 13, p. 114.
} 
Esse caminho de conhecimento, próprio às ciências, de descer do universal ao particular, torna necessário que por ele muita coisa seja fundamentada por dedução a partir de princípios precedentes, logo, por demonstrações, o que ocasionou o velho erro de que só aquilo que é demonstrado é completamente verdadeiro, e cada verdade exigiria uma demonstração. Antes, ao contrário, cada demonstração precisa de uma verdade indemonstrável que em última instância sustenta a ela ou à sua demonstração ${ }^{7}$.

Dessa maneira, a ciência moral deve estar fundada sobre uma verdade indemonstrável que, como afirma o texto mais adiante, é dada pela intuição, seja ela pura e, portanto, a priori, seja ela empírica e, portanto, a posteriori. Como parece indicar o filósofo, a ciência moral aparece fundamentada sobre a intuição empírica da ocorrência de ações morais, quer dizer, a ciência moral está fundamentada sobre a verdade indemonstrável de que a moral está dada empiricamente. No entanto, se a moral como verdade indemonstrável advém a nós por meio da experiência, contestamos ainda: no âmbito fenomênico, qual é a prova do fato?

Insistamos na pergunta: o que garante que existe ao menos um justo nesta imensa Sodoma que é o mundo? Schopenhauer, convencido pela experiência empírica, declara: "há de fato pessoas verdadeiramente honestas como há também realmente trevos de quatro

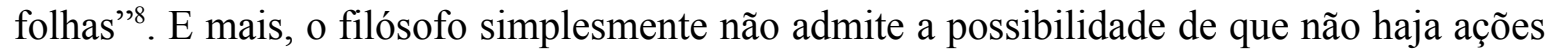
morais e, mais à frente no texto, escreve: “(...) se alguém persistisse em negar a ocorrência de tais ações, então a moral segundo esse alguém seria uma ciência sem objeto real, igual à astrologia e à alquimia, e seria tempo perdido discutir mais sobre seu fundamento. Eu pararia de falar com ele e continuaria falando com aqueles que admitem a realidade do fato"

Sejamos, pois, céticos com relação a esse argumento. O que mostra que a moral está dada na intuição empírica como verdade indemonstrável? Como a vontade do indivíduo pode deixar de ter em vista a satisfação própria, para visar à satisfação alheia, quer dizer, como o sujeito pode deixar de querer o que ele quer para querer o que outro sujeito quer?

\footnotetext{
${ }^{7}$ SCHOPENHAUER, A. O mundo como vontade e como representação, tomo I, $\S 14$, p. 115-116. Doravante abreviado como "MVR I".

${ }^{8}$ SCHOPENHAUER, A. M, $\S 13$, p. 114-115.

${ }^{9}$ SCHOPENHAUER, A. M, §15, p.130.
} 
Pois, como já sabemos, se ele for movido pelo interesse próprio a ação é egoísta e não possui valor moral.

Além disso, o trecho da última citação acima, no qual Schopenhauer escreve: "a moral segundo esse alguém seria uma ciência sem objeto real", pode ser interpretado da seguinte maneira: "existe um objeto real, porque existe uma ciência desse objeto", o que se caracteriza como uma petitio principii, pois a proposição "existe ação moral" está pressuposta implicitamente na premissa dada como válida, a saber, "existe ciência moral"; para usar termos lógicos, o consequente está pressuposto implicitamente no antecedente e, portanto, não há prova do consequente, apenas sua pressuposição, fazendo-o passar despercebido no argumento, para depois, no momento certo, saltar para fora desse, tal qual um coelho de uma cartola sobre o qual se exclama: eis que ele foi tirado da cartola! Como se já não estivesse, nela, escondido. Desse modo, dizer que a ação moral existe porque existe ciência da moral é tão verdadeiro quanto dizer que existe a pedra filosofal porque existe alquimia. Assim, não é o caso que existe ação moral por existir ciência da moral.

Finalmente, questionemos não mais o argumento de Schopenhauer de que existe ação dotada de valor moral e ela está dada pela experiência empírica, mas, desta vez, diferentemente do que fizemos com o critério de determinação de atribuição de valor moral, não concedamos o argumento e inquiramos, em última análise, o seguinte: qual é a chave de interpretação que permite Schopenhauer assumir a existência de ações dotadas de valor moral?

Ora, se o fundamento da ação de pura caridade e justiça não pode ser dado pela experiência empírica - e Schopenhauer indica isso ${ }^{10}$ - o que pode, então, nos dar a certeza de tais ações? O fundamento último e a garantia de que existe ação moral está na metafísica.

Certamente este processo é digno de espanto e até misterioso. É, na verdade, o grande mistério da ética, seu fenômeno originário e o marco além do qual só a especulação metafísica pode arriscar um passo. Vemos neste processo a supressão da parede divisória que (...) separa inteiramente um ser de outro ser, e vemos o não-eu tornar-se numa certa medida o $e u^{11}$.

\footnotetext{
${ }^{10} \mathrm{Cf}$, por exemplo, SCHOPENHAUER, A. M, §22, p. 210.

${ }^{11}$ SCHOPENHAUER, A. M, §16, p. 136.
} 


\section{Sobre o fundamento metafísico}

Admitindo que à base do fenômeno da ação a que se atribui valor moral está a metafísica da Vontade, Schopenhauer indica que o que determina a ação moral não é um fenômeno, mas a essência por trás desse fenômeno.

Pode-se interpretar que o filósofo perfaz o caminho entre ação moral e a metafísica de duas maneiras: a primeira pode ser dita sintética, pois parte do universal para determinar o particular; e a segunda maneira pode ser dita analítica, pois parte do particular sendo determinado pelo universal. Importante ressaltar que as duas maneiras de argumentar rezam sobre um e mesmo fenômeno: a ação moral. Não há duas formas de se agir moralmente, apenas duas maneiras de explicitar como o fenômeno da ação moral se fundamenta sobre a metafísica. Tanto uma maneira quanto a outra, estão presentes em Sobre o Fundamento da Moral e no tomo I de O Mundo como Vontade e como Representação na mesma seqüência, a saber, sintética e analítica.

Deixando o método de lado por um instante e seguindo a linha argumentativa do filósofo, podemos encontrar a definição de bom e mau, as quais aplicadas às ações coincidem com a presença ou ausência de valor moral respectivamente. Assim, bom é "tudo aquilo o que está de acordo com os desejos de alguma vontade individual"12 e disso provém "boa comida", "bom caminho" etc., e quando se aplica à ação, "boa ação". No entanto, se bom é aquilo que está de acordo com uma vontade particular, como é possível algo ser definitivamente bom? Em outras palavras, como se passa da definição "homem que realiza boas-ações” para “bom homem”? A resposta é: quando a essência daquele homem é boa, ou seja, quando o que é bom não está apenas de acordo com o particular, mas está assim definido pelo universal, sim, pela Vontade em si.

Logo, um bom homem é aquele que pratica boas-ações por que isso está na sua essência, no seu caráter. Dessa forma, não é por praticar boas ações que alguém é bom, mas por ser bom é que se pratica boas ações. Não obstante, resta saber: o que determina o caráter? Nas palavras de Schopenhauer: "Nesse modo mesmo de agir manifesta-se seu caráter empírico; por seu turno, neste manifesta-se de novo seu caráter inteligível, a

\footnotetext{
${ }^{12}$ SCHOPENHAUER, A. M, § 22, p. 211.
} 
Vontade em si, da qual aquele é o fenômeno determinado" ${ }^{13}$. Eis, pois, que é a própria Vontade em si que constitui o caráter de determinada maneira e é a isso que se deve o modo de agir do indivíduo.

Assim, alguém faz boas-ações - que são aquelas a que se atribui valor moral ${ }^{14}$-, pois isto está em seu caráter que é constituído e determinado pela Vontade em si. Esse modo de argumentar pode ser dito sintético porque parte do universal para o particular, no seguinte sentido: a Vontade em si, que constitui a essência do mundo constitui também o caráter do indivíduo fazendo com que este seja mais sensível a praticar ações morais. Desse modo, o que garante que existem ações que visam ao bem-estar alheio é a determinação da Vontade em si.

Por outro lado, agora do modo que se pode dizer analítico, e, portanto, partindo do fenômeno particular, o homem age visando apenas à satisfação alheia - não apenas de modo aparente, mas uma ação moral de fato -, quando reconhece os outros indivíduos como sujeitos da mesma Vontade. De tal forma isso ocorre que o sujeito se identifica com o outro e sofre com ele, vale dizer, sente o sofrimento do indivíduo alheio no individuo alheio, mas, no entanto, sofre conjuntamente. E, para estancar a fonte do sofrimento, age de modo benéfico para com o indivíduo alheio, tendo em vista a cessação do sofrimento sentido em conjunto; "o sofrimento é dele, mas eu também o sinto" diria o agente; e ainda "eu sofro o sofrimento dele com ele". Mas, se ele também sofre e age de modo com que esse sofrimento cesse, essa ação não visaria ao interesse próprio? Não! Pois o sujeito da ação não sofre por si, mas sofre com o outro porque se identifica com ele. Todavia, não basta reconhecer o outro como um sujeito que possui vontade, alguém que quer e sofre por isso; para que haja a identificação, o sujeito que age tem de reconhecer no indivíduo alheio a mesma Vontade que há nele, o que é impossível pela via fenomênica, onde reside toda a diversidade entre indivíduos. Assim, para que o sujeito reconheça a vontade que sente em si mesmo, com a vontade presente no indivíduo exterior a ele como fenômenos distintos de uma mesma essência, faz-se necessário uma intuição imediata, que mostra ao sujeito que ele e o outro são a mesmíssima Vontade e que toda diferença entre eles reside apenas no fenômeno. Sobre isso, Schopenhauer escreve:

\footnotetext{
${ }^{13}$ SCHOPENHAUER, A. MVR I, § 55, p. 372.

${ }^{14} C f$. SCHOPENHAUER, A. MVR I, $\S 65$.
} 
Pois àquele que pratica obras de amor, o Véu de Maia se torna transparente e a ilusão do principii indivuiduationis o abandona. Reconhece a si mesmo, à sua vontade, em cada ser, consequentemente também em quem sofre (...). Ser curado dessa ilusão e engano de Maia e praticar obras de amor são uma única e mesma coisa. Estas últimas obras, entretanto, são sintomas inevitáveis e infalíveis daquele conhecimento ${ }^{15}$.

Dessa maneira, o que garante a existência de fato da ação moral é a identificação que ocorre entre o eu e o não-eu, ou ainda, entre o sujeito da ação e o indivíduo alheio, na qual aquele se vê idêntico a este, não como fenômeno, mas como Vontade em si, por meio de um conhecimento intuitivo e imediato, ao qual não se pode ser indiferente, isto é, a posse desse conhecimento, inevitavelmente, determina a realização de boas-ações.

Esse argumento pode ser dito analítico no sentido de que ele parte do indivíduo que se identifica com outro na medida em que reconhece neles a mesma Vontade.

Os argumentos aos quais atribuímos a qualidade de sintético e analítico dizem respeito a uma e mesma coisa, a saber, à fundamentação da moral na metafísica, tendo como única diferença o caminho argumentativo percorrido para tal fundamentação. Apesar de ser possível separá-los em dois movimentos, o fenômeno é o mesmo. No movimento argumentativo sintético é a Vontade que determina o caráter que, por sua vez, determina o agir moral; assim, o que liga o universal ao particular é o caráter. Já no movimento argumentativo analítico o sujeito age moralmente porque se identifica com um outro indivíduo na medida em que reconhece neles a mesma Vontade; assim o que liga o particular ao universal é a identificação. No entanto, na ação moral, caráter e identificação não são separáveis, um e outro são o mesmo fenômeno visto de ângulos diferentes.

Assim, em última instância é, novamente, a metafísica da Vontade que está na base desses fenômenos, e que se mostra como a chave interpretativa que possibilita a existência da ação a que Schopenhauer atribui valor moral, o que equivale a dizer: a existência de toda ação a que se atribui valor moral depende da determinação metafísica.

\section{Conclusão}

\footnotetext{
${ }^{15}$ SCHOPENHAUER, A. MVR I, § 66, p. 474.
} 
Uma vez estabelecido o critério para se atribuir valor moral, a saber, a ausência de motivação egoísta, nos deparamos com o filósofo recorrendo à consciência moral para livrar da atribuição moral as ações maldosas. Questionamos, em última análise, qual, então, é o critério da consciência moral na atribuição de valor. A resposta não está aparente e precisamos adotar o critério para só depois compreendê-lo.

A existência da ação a que se atribui valor moral posta em questão fez surgirem muitas dúvidas sobre sua motivação. Muito questionou-se o que determina a existência da ação a que se atribui valor moral, apesar da convicção do autor em afirmar que a experiência empírica as apresenta indubitavelmente. Seguimos a diante com a indicação de Schopenhauer de que todo esse fenômeno se fundamenta na metafísica

Finalmente, é a metafísica da Vontade que determina que certas ações não sejam motivadas pelo bem-estar do sujeito que age, mas de acordo com a vontade alheia, o que não só garante sua existência, mas também possibilita a atribuição de valor moral à ação, não pelo que é na aparência, mas pelo que é na essência. A resposta à questão do critério se apresenta aqui: a boa-ação a que se atribui valor moral não possui seu fundamento no fenômeno - onde uma ação puramente má ou cruel pode satisfazer uma vontade particular e, assim, ser boa - mas na metafísica da Vontade que determina que a ação do sujeito tenha em vista unicamente a satisfação de outro indivíduo. Admitindo-se o critério de atribuição de valor moral, concluímos que o fundamento de toda atribuição desse tipo de valor está na metafísica da Vontade e dela não pode prescindir.

\section{Referências}

SCHOPENHAUER, Arthur. O Mundo como Vontade e como Representação, $1^{\circ}$ Tomo; Tradução, apresentação, notas e índices de Jair Barboza. São Paulo: Editora UNESP, 2005.

ed. - São Paulo: Martins Fontes, 2001 Sobre o Fundamento da Moral; Tradução Maria Lucia Cacciola. - $2^{\mathrm{a}}$ - Los dos problemas fundamentales de la etica; Traduccion, introduccion y notas Pilar Lopez de Santa Maria. Madrid : Siglo XXI de Espana, 1993

. Parerga and Paralipomena - Short Philosophical Essays; Translated from German by E.F.J. Payne - volume one. Oxford: Claredon Press, 2000.

. Parerga and Paralipomena - Short Philosophical Essays; Translated from German by E.F.J. Payne - volume two. Oxford: Claredon Press, 2000. 
Revista Voluntas: estudos sobre Schopenhauer - $1^{\circ}$ semestre 2011 - Vol. 2 - No 1 - ISSN: 2179-3786 - pp. 22-31

. Aforismos para a Sabedoria de Vida; Tradução prefácio e notas de Jair Barboza. São Paulo: Martins Fontes, 2002

. De la Quadruple Racine du Principe de Raison Suffisante. - $2^{\mathrm{a}}$ ed. Presentation, traduction e note par François-Xavier CHENET ; Paris: Librairie Philosophique J. Vrin, 1997.

Recebido: 20/05/11

Received: 05/20/11

Aprovado: 29/06/11

Approved: 06/29/11 